\title{
Digital skills and their development in the Czech Republic
}

\author{
Eva Kasparova ${ }^{1}$ \\ ${ }^{1}$ Department of Managerial Psychology and Sociology, Faculty of Business Administration, \\ University of Economics in Prague
}

\section{Article Info}

Received Mar 2, 2019

\section{Keyword:}

digital skills, digitization, labour market, learning,

ICT

\begin{abstract}
The process of digitization keeps accelerating and the consequences of the transformation of the existing traditional practices is manifesting in all areas of human life. However, technological advances bring a whole range of significant changes that put increased demands on both their adoption and their successful management and, last but not least, the continued effective improvement of the development. To meet these requirements and to ensure the efficiency of transformation processes associated with growing digitization, digital skills are an indispensable necessity. Digital skills are the core stone of the 4.0 industrial revolution. The paper analyses the state of digital skills in the Czech Republic in the years 2014-2016. The Czech Republic is developing a number of initiatives to contribute to the development of digital skills. However, it is important to build a closer relationship and cooperation between industry, research centres and universities to reflect the reality effectively and appropriately. The document draws conclusions and makes recommendations based on the research findings, which are the subject of discussion.
\end{abstract}

\section{Corresponding Author:}

Eva Kasparova ${ }^{1}$

${ }^{1}$ Department of Managerial Psychology and Sociology, Faculty of Business Administration,

University of Economics in Prague

W. Churchilla 4

13067 Prague 3, Czech Republic

Email: kasparov@vse.cz

\section{Introduction}

The process of digitization rapidly influences both the labour market and the very nature of human work. The fundamental continuous technological changes that are currently taking place are very significant in the area of employment and work conditions as well as levels and income distribution. Alongside investments in modern technology development, it is very important to invest in skills and knowledge to be appropriately prepared for the labour market needs in near future.

Even in professions where the necessity for digital competences was not required at present, it is found that they do or will need at least basic digital knowledge and skills, among which can be included: ability to search for relevant information on the Internet and to e-communicate and use e-nets. Working with a PC or the access on Internet has become a necessary part of daily life of most of us. 
Information and communications technologies present still more and more significant place in human life both professional and personal, and digital skills started to be a routine part of the most social activities for each of us. It can be expected that in the next few years all professions will need specific digital skills. [1]

The UK's Industrial Strategy predicts that within next two decades, 90\% of existed jobs will request some digital proficiency. [2] At present, however, more the $44 \%$ of European citizens it does not have elementary digital skills. Almost $37 \%$ of the labour market population cannot offer the required digital skills, even though digital competences are increasingly required in all present positions. [1] The practical examples of the implementation of sophisticated applications in different industries and services with the aim of improvement processes and product/service quality shows the necessary knowledge and skills to use these applications adequately. [3] [4]

In the end, the absence of basic digital knowledge and skills may be the cause of inefficient work, and the employee may become too expensive for the employer. A "digitally illiterate" employee becomes inefficient for the company and can cause financial loss for businesses. The employees who do not effectively use digital technology because of their lack of technology skills need more time for solving problems, completing the tasks etc. Another quite a serious problem relates to security risks when insufficiently skilled employee moving on the Internet. There is a risk of loss or misuse of contacts, data, and consequently also financial damage.

The serious problem of employers is the high cost of training new employees. However, the main shortage is the content of corporate training that focuses mainly on specialized areas and often completely overlooks the critical lack of basic digital knowledge and skills. The lack of training can result in low flexibility and usability of the employee, and the inability to move staff from one job to another.

In the first part, the paper specifies the term digital skills. Then the author informs about current market requirements in the Czech Republic and existing initiatives for the development of digital skills by the state. In the next part, the paper presents the results of the secondary analysis of data from the annual statistical survey entitled "ICT Use in Households and by Individuals", which the Czech Statistical Office realized in 2017. [5] The paper focuses on selected aspects of digital skills in the monitored population aged 16+ using the Internet for selected activities; 2014-2016, for which it presents specific optimization suggestions and recommendations. The conclusion summarizes these findings and encourages us to manage effectively the changes in the period of 4.0 and to optimize the development of our readiness and the ability to accept digitization adequately of course not only in the Czech Republic.

\section{The Digital Skills}

However, employers themselves quite often do not know how to test digital skills. The major problem is that employers fail to name what exactly they need from their employees, or they assume the basic digital skills that employees have. Understanding the content of digital skills, in other words, what digital skills are and what skills are desirable in this area is not entirely consistent and often unclear.

As Walton wrote, quite a lot of definitions of digital literacy exists at present. [6] These definitions can be summarized and generally stated that digital competences are any skills related to being digitally literate. The definition of digital competence itself is an important and first step that leads to the demand for digital literacy to be fulfilled. The primary task is then to prepare teachers appropriately, who will be able to pass on the knowledge and skills to pupils and students so that they are appropriately equipped for practice. [7]

The definition of what digital competence is relatively wide. In fact, the spectrum of knowledge and skills ranges from simple to advanced, allowing the user to use the technology. The Organization for Economic Cooperation and Development distinguishes fundamental types of ICT required skills in the workplace.

The one of the most important type relates to basic skills; it is an ability to use the digital technologies for professional purposes, i.e. work with the information online or use of the software. The other type is focused on specific competences, which are essential for the creation of new information technology production as well as services, for example in the field of programming, new applications development, networks building 
and organizing etc. The complementary competences are important for the tasks related with ICT usage i.e. handling with information, ability to e- communicate, ability to solve a problems etc. The fourth type - the generic competences can be identified as appropriate digital literacy and emotional and social competences for the usage of modern technologies. Consequently, the ability acquire these competences is a very important part of meeting digital competence requirements. [8]

The Essential Digital Skills Framework defines several categories of the skills needed to adapt and adequately embrace the current cyber-physical world as well as its future development. One of these categories is focused on communication. The other on work with information and the content. The equally important is the ability to make different transactions as well as the ability of problem solving. Currently is the very significant the type focuses on safety and legality to be online.

The key goal is for all the people to have the crucial set of skills essential for the universal development of each individual, social life, participation in public activities and employment. Besides the skills, which contain numeracy, literacy, science and foreign languages the main attention is at present focuses on the digital competence. [9]

Europe has long been faced with a noticeable lack of skilled ICT workers in the labour market. The result of this disproportion is the growing number of vacancies for these specialists in all sectors of the economy. A crucial challenge is the need to fundamentally modernize existing education and training systems, which are currently not sufficiently preparing young people for the digital economy and society. The starting point for this could be to transform the existing learning system into a lifelong learning system. Lifelong learning better reflects contemporary demands and is a more appropriate response to rapid and permanent changes that are evident in all areas of human life and society. [1]

\section{Digital skills in the Czech Republic}

\subsection{Importance of digital skills development in the Czech Republic}

In 2015, the Czech government accepted a new Digital literacy strategy for the period 2015-20. [10] The strategy is a joint initiative of the Ministry of Education, Youth and Sports (MŠMT) and the Ministry of Labour and Social Affairs (MPSV). It is related to the following European strategies and national programs. The strategy adopts a comprehensive approach to achieving this. It covers most aspects of how ICT influence individuals in all aspects of life: employment, entrepreneurship, social life, family life, public services as well as the education. Various measures and initiatives are foreseen in each of these areas of a strategy for promoting digital literacy.

The main purpose of the proposed measures is

- to improve the digital literacy of people threatened by unemployment

- to support employees and workers in small and medium-sized enterprises and self-employed people who lack the necessary level of digital literacy due to the rising industry trends 4.0

- to support the socially and digitally excluded individuals and groups

- to support families to use of the opportunities that the digital technologies provide

- to increase digitization of public services

- to increase education through digital technologies [10]

The international conference, "The Digital Czech Republic" which was held in February 2018 states that the essential task of the state is to guarantee high-quality education for children. It must also address the growing demand of the labour market for digitally literate workers [11]. This results in the need to transform the system into a truly lifelong learning experience in which universities serve as partners to both employees and employers. 
The conference proclaims that the education system must keep the pace with the changing labour market and must be able to change flexibly the ways in which it prepares students for their future jobs. Further, the Act on the Verification and Recognition of Further Education Outcomes (No. 179/2006 Coll.) should be amended to create a path equivalent to initial education in order to achieve the necessary qualifications on the labour market. A career guide should be available to students who need help with choosing their academic direction and selecting their courses. [11]

The Czech Republic creates and consolidates the necessary basis for acquiring and developing digital skills of the entire Czech population.

\subsection{Research goal}

The purpose of the research is to evaluate the development of digital skills in the Czech Republic by analysing the state of the digital skills in 2014-2016.

\section{The survey on the Information Society in the Czech Republic}

\subsection{Methodology}

The author performed a secondary analysis of the data from this statistical survey and used the findings to evaluate the current state of digital skills in the Czech Republic in 2014-2016. [12] The Czech Statistical Office uses three sources to monitor ICT use in schools:

The main source comes from the Ministry of Education, Youth and Sports, which collects data on computer and internet use in primary, secondary, and higher professional schools.

The second source is the Universities' web survey carried out by the Czech Statistical Office, and focuses on information access and on-line services offered on university web sites.

The findings on the use of the Internet are available in a report from the Czech Statistical Office's annual statistical survey entitled "Use of ICT in households and individuals". [5] In particular, the data point to students who used the Internet at least once in the last 3 months, be it from home, work, school, etc. and for whatever reason, i.e. for personal use, work needs, etc. The survey also includes activities that students undertake through the Internet for personal non-business use in the last 3 months and online purchases or use of the Internet to deal with public authorities over the past 12 months. [5]

\subsection{Secondary analysis of the survey findings in the Czech Republic in 2014-2016}

The findings of the survey Information society in Figures, which the Czech Statistical Office conducted in 2014-2016 shows differences between males and females, aged 16+ using the Internet for selected activities as well as differences in the proportionality of the monitored activities. [12] The smallest share of respondents, 5, $8 \%$ in total takes online courses. In comparison, in an international survey conducted in the Czech Republic and Latvia in 2017, it was found that the highest number of participants (almost 50\% in both countries) had never taken any online learning course. [13] As for the need for a purposeful preparation of the young generation, using the modern ICT in education is particularly important.

However, the online learning area has considerable shortcomings in the Czech Republic. The reason could be the total area of the Czech Republic and the good transport accessibility of schools in the Czech Republic. On the other hand, online courses could more closely link the academic sphere to the corporate sphere, for example the opportunity to participate online to solve specific practical tasks. Online courses would extend international team collaboration opportunities. Transferring a certain amount of study load into the virtual 
environment allows both students and lecturers to save time and offer the flexibility of studying without having to attend a classroom lecture.

The use of online learning materials, in total $30,7 \%$, also has considerable shortcomings.

Table 1: Students in the Czech Republic aged 16+ using the internet for selected activities; 2014-2016 [12]

\begin{tabular}{l|r|r|r}
\hline & Total & Males & Females \\
\hline Using the Internet & $\mathbf{9 9 , 1}$ & $\mathbf{9 8 , 9}$ & $\mathbf{9 9 , 4}$ \\
Using mobile connections & 78,3 & 75,6 & 77,0 \\
Using the Internet for learning activities: & & & \\
On-line course & 5,8 & 4,6 & 7,1 \\
Using on-line learning material & 30,7 & 26,0 & 35,5 \\
Communication with instructors or other students & 27,1 & 25,1 & 29,2 \\
Using the Internet for other activities: & & & \\
Participating in social networks & 93,0 & 94,2 & 93,6 \\
Listening to web radio & 45,9 & 46,5 & 46,2 \\
Reading online news & 82,5 & 83,9 & 83,2 \\
Telephoning over the Internet & 65,4 & 65,0 & 65,2 \\
Playing games & 77,4 & 47,6 & 62,7 \\
Searching for travel-related information & 55,0 & 65,4 & 60,1 \\
Watching TV & 45,9 & 44,2 & 45,1 \\
Purchasing over the Internet & 37,0 & 36,9 & 36,9 \\
Internet banking & 32,4 & 33,8 & 33,1 \\
\hline
\end{tabular}

as a percentage of all students aged $16+$ in a given group

As it turns out, the need to teach students to be more independent in searching for information and working with data and existing knowledge is still very topical in the Czech Republic. For the period 4.0, this skill will become more and more important. The ability to find the necessary data or information in time, to be able to work with it, to analyse it, to share it with other actors important in solving the given task is already a prerequisite for applying for a job in many branches of the current labour market.

The highest percentage of monitored activities clearly belongs to participating in social networks. As can be seen, the area of social networks offers a space that has not yet been used to develop new educational methods. Similarly, game playing receives a lot of interest from both monitored groups of 16+ students i.e. males and females. There also seems to be a big challenge for programmers of special games, which could be used as effective study material. Figure 1 shows quite a big difference between students and individuals aged $16+$ participating in social networks.

$93 \%$ of students in total participate in social networks in comparison to $39 \%$ of all individuals. In addition, there is a very clearly visible preference of using social networks at first among students. It is advisable to make greater use of the potential of social networks for educational purposes in a situation where social networks are very popular among students.

It can be deduced from the graph that the percentage of monitored activities for all individuals is related to the usefulness of a specific activity. As can be seen from the graph, $64 \%$ of all individuals read news online and $45 \%$ use internet banking. This raises the question of whether it would be appropriate to extend the range of training programs to social networking opportunities in the work process, marketing, PR, etc., in order to show their practicality and usefulness in various areas of life. Similarly, it can be recommended to prepare training programs for effective use of e-health, e-government, etc. i.e. other useful areas such as internet banking. 
Figure 1: Students and individuals aged 16+ using the Internet for selected activities; 2014-2016 [12]

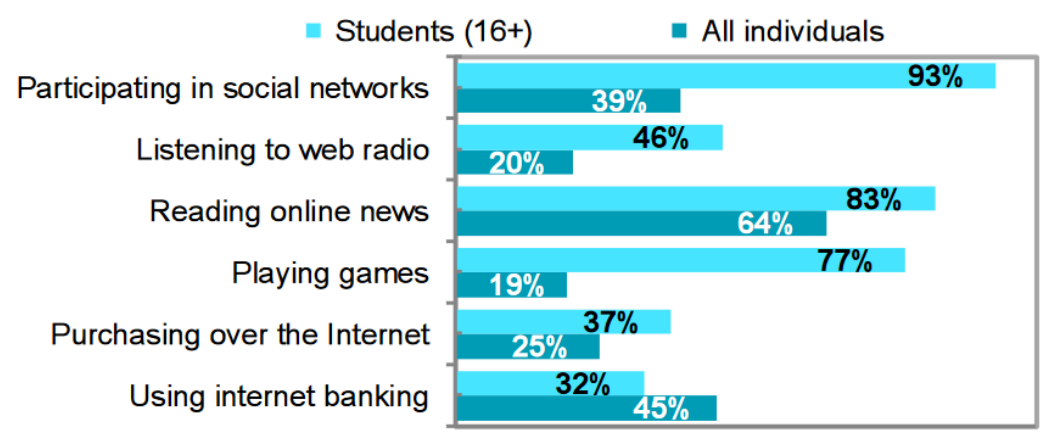

* numbers are moving average calculated for years 2014-2016

as a percentage of students and all individuals who have used the Internet in the last 3 months

Figure 2 illustrates still higher percentage of internet users both in the group of students and in the group of all individuals. It can be said that for current students in the Czech Republic Internet usage is already a normal part of life. With a growing number of mobile devices and a range of Internet connectivity options, most of students can actually have access to the Internet permanently. This fact could again be used more in education for better preparedness for the transformation processes in 4.0.

Figure 2: Students and individuals aged 16+ accesing the Internet via mobile phone by type of connection [12]

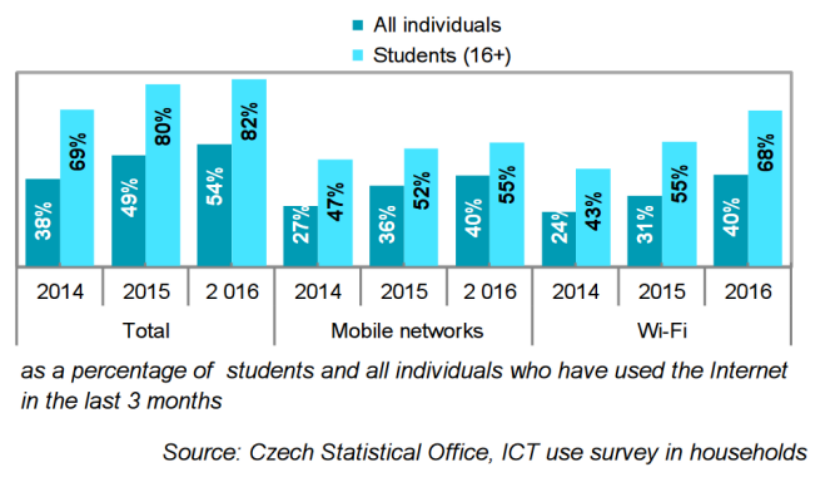

Students can search for the right information and collect data online anytime to achieve better problem's solving, task fulfilment and completing other duties during the learning process. All individuals can of course use digital skills in their practical life as well. However, the gap between expectations and opportunities in ICT usage and their real usage still exists. Therefore, it is important to build a closer relationship and cooperation between industry, research centres and universities to reflect the reality effectively and appropriately.

\section{Conclusion}

The new ICT is expanding and multiplying. The development of new types of mobile devices is getting faster and faster. Digitization penetrates all areas of human life. The Czech Republic is developing a number of initiatives to contribute to the development of digital skills as desirable both in the labour market and in all other areas of life similarly as the other member countries of EU in line with EU intentions. [13]

The Czech Republic constantly contributes to the fulfilment of the aim to support digital competences, which are becoming one of the basic requirements for most professions as well as jobs in line with the development and demands of Industry 4.0.

However, there is still a need to be in close contact with developers of new technologies, with their providers as well as with their users. There is a need to strengthen cooperation between government, industry and academia to ensure both the required development of modern technologies and their appropriate 
adaptation and usage. The very important task of the effective management of modern systems and transformation processes associated with their implementation is still topical and demanding the necessary solution. Continuous monitoring and analysing of the development of digital skills is important in the coming years as well. The results of the analyses will serve to precise formulation of tasks and proposals for innovative measures that will lead to the desired preparedness of the Czech population to digitize in an optimal way and to react effectively to the changes.

\section{References:}

[1] Kiss M. "Digital Skills in the EU labour market". EPRS European Parliamentary Research Service, Members' Research Service, January 2017 - PE 595.889. ISBN 978-92-846-0367-1.

[2] House of Commons Science and technology Committee. "Digital Skills crisis". London: House of Commons Science and technology Committee, 7 June 2016. 47p.

[3] Hrvacic I. „Design and Implementation of SPC Systems in Defense Industry Manufacturing Process“. Periodicals of Engineering and Natural Sciences. 6(1): 99. 27-40. 2018

[4] Durakovic B. „Design of Experiments Application, Concepts, Examples: State of the Art.“ Periodicals of Engineering and Natural Sciences. 5(3): pp. 421-439. 2017

[5] Czech Statistical Office. "Digitální dovednosti”. Prague: Czech Statistical Office, 2018. [Consulted 2019-

05-30]. Retrieved from CZO website: https://www.czso.cz/csu/czso/digitalni-dovednosti-2018

[6] Walton G. "Digital Literacy" (DL): Establishing the Boundaries and Identifying the Partners. New Review of Academic Librarianship. 22(1): pp.1-4. 2016.

[7] Ulmane-Ozolina L, Jansone A, Magazeina I, Barute D. „Technology enhanced learning in teachers' professional development“. Periodicals of Engineering and Natural Sciences. 7(1): pp. 216-21. 2019

[8] Berzina D. Learning by doing. „Case study: education for sustainable development at the University of Latvia“. Periodicals of Engineering and Natural Sciences. 7(1): pp.156-64. 2019

[9] EOCD. "The Future of Education and Skills: Education 2030. The Future We Want." Paris: OECD Publishing; 2018. 21 p.

[10] Czech Republic: MoLSA. "Strategie digitální gramotnosti ČR na období 2015 - 2020”. Prague: The Ministry of Labour and Social Affairs (MoLSA), 2015. 94 p.

[11] Instutitute for Politics and Society. "PANEL A: Education for the 21 st Century." International Conference Digital Czech Republic 2018. Prague: Institute for Politics and Society; pp. 10-1. 2018.

[12] Czech Statistical Office. "Information society in figures - 2017”. Prague: Czech Statistical Office, 2017.

Publication code: 061005-17 Ref. no.: 954/2017-63 [Consulted 2019-05-30]. Retrieved from CZO website: https://www.czso.cz/csu/czso/information-society-in-figures-2014-2016

[13] Mirke E., Kašparová E. and Cakula S. “Adults' readiness for online learning in the Czech Republic and Latvia (digital competence as a result of ICT education policy and information society development strategy)". Periodicals of Engineering and Natural Sciences. 7(1): pp. 205-15. 2019. 